\title{
Direitos e/ou povos e comunidades tradicionais: noções de classificação em disputa
}

\section{Rights and/or Traditional Peoples and Communities: Notions of Classification in Dispute}

\author{
Assis da Costa OLIVEIRA*
}

\begin{abstract}
RESUMO
Os cenários de construção das bases teórico-normativas da categoria povos e comunidades tradicionais são analisados no presente artigo para identificação dos pontos de disputa de classificação e os dilemas decorrentes da (in)compatibilidade entre identidades/dinâmicas culturais e categorias analíticas. A articulação da Antropologia com o Direito possibilita empreender a valorização das autodefinições dos agentes oriundos de povos e comunidades tradicionais, assim como desconstruir as condições ideológicas do campo jurídico via reinterpretação da tradição e do direito à participação como pré-requisitos para a transformação dos grupos em sujeitos de direitos - destinatários de normas jurídicas - e em sujeitos do direito - produtores e administradores das normas jurídicas que lhes cabem.
\end{abstract}

Palavras-chave: povos e comunidades tradicionais; direitos coletivos; identidade cultural; Antropologia do Direito.

\begin{abstract}
The scenarios of building the foundations of the theoretical and normative category of traditional peoples and communities are analyzed in this article to identify the points of dispute of classification and dilemmas arising from the (in)compatibility between identity /cultural dynamics and analytic categories. The articulation of Anthropology with the Law would allow to undertake the valuation of self-definitions of the operator from traditional peoples and communities, as well as deconstructing the ideological conditions of the legal field through reinterpretation of tradition and the right to participate as a prerequisite for the transformation of groups into subjects of rights - the addressees of legal norms - and into subjects of law - producers and managers of the legal rules that fit them.
\end{abstract}

Keywords: traditional peoples and communities; collective rights; cultural identity; Anthropology of Law.

\footnotetext{
"Mestre em Direito (UFPA). Professor da Faculdade de Etnodesenvolvimento da Universidade Federal do Pará (UFPA) e associado do Instituto de Pesquisa Direitos e Movimentos Sociais (IPDMS). E-mail: assisdco@gmail.com
} 
"Antes dos portugueses chegarem, Cada lugar de nossa terra tinha um nome.

Mas logo, os portugueses trocaram os nomes de tudo.

O lugar onde eles encostaram as caravelas eles chamaram de Porto Seguro.

$\mathrm{O}$ primeiro morro que eles enxergaram, eles chamaram de Monte Pascoal.

Os Tupinikim já tinham dado nome para esses lugares.

Os portugueses mudaram o nome da terra. Mas não mudaram só o nome da terra. Os portugueses roubaram a terra também."

(CIMI, 1982)

A epígrafe descrita acima faz parte de poesia produzida por pessoa indígena, inserida numa coletânea de poesias publicada pelo Conselho Indigenista Missionário (CIMI, 1982) para traduzir, do ponto de vista dos indígenas, o que foi a história do território ameríndio nos últimos 500 anos de luta contra o colonialismo e o capitalismo ocidentais.

Sintetiza, em poucas palavras, a primeira grande dominação imposta aos grupos nativos: a simbólica, ligada ao domínio da linguagem, mas, sobretudo, ao poder de representar a realidade. Desde o momento em que a invasão portuguesa se consolidou no território, as formas de representar a diferença foram sistematicamente manipuladas para justificar relações de poder assimétricas, dispostas de maneira antagônica ou polarizada - como primitivo e civilizado - para hierarquizar vidas e sociedades, relegando muitos sujeitos à condição de subumanos e aos "pares" ocidentais o status de "profetas do apocalipse", é dizer, de porta-vozes das boas-novas de aculturação que misturavam a necessidade de dizimar para lucrar com a benevolência da transformação do "selvagem" no bom cidadão.

Afinal de contas, se tudo já tinha sido nomeado, cabia agora não apenas renomear, mas instaurar juízos de valores no antes - concebido como pré-história do contato - e no depois - concebido como história do Brasil -, dignificando os dizeres "modernos" pelo simples fato de serem "modernos" e possibilitando incluir entre as coisas recém-descobertas, logo, recém-nomeadas, todos os grupos com os quais se estabeleciam relações políticas de opressão. De forma a construir imagens sociais, tornadas senso comum ao longo dos séculos, que não somente retiraram a primazia linguística dos Tupinikim, mas instituíram a legitimidade da representação da alteridade cultural - a invenção do índio, do quilombo, do camponês, entre outros - e garantiram o roubo de suas terras e o início de lutas intermináveis.

No jogo simbólico e político do poder, o saber construído elaborava estereótipos representacionais para excluir os sujeitos das garantias jurídicas e morais. Logo, tratava-se, em suma, de manipular imagens para inviabilizar direitos.

Todavia, em pouco mais de 30 anos, em pleno século $\mathrm{XX}$, as condições históricas, políticas e simbólicas são transformadas pela lógica da autonomia, cidadania diferenciada e sustentabilidade dos grupos sociais diferenciados.

No contexto da expansão dos direitos humanos no âmbito internacional, pós-II Guerra Mundial, e da ascensão político-organizacional das coletividades diferenciadas étnico-culturalmente, a cristalização dos destinatários dos direitos passa a assumir outra dinâmica: se, antes, tratava-se de manipular simbolicamente para excluir a possibilidade de inserção jurídica, agora a manipulação está nas formas de inclusão jurídica, via definição de critérios que buscam autorizar não somente quem são os destinatários dos direitos coletivos específicos, como também qual o rol de atributos e atribuições que os mesmos devem (su)portar (ou serem seduzidos a adotar) para que possam permanecer incluídos na categoria jurídica que lhes transmuta em sujeitos de direitos, ainda que a própria permanência não seja garantia de proteção dos direitos, haja vista, por exemplo, os interesses governamentais e empresariais que conseguem justificar o desrespeito aos direitos pela retórica do desenvolvimento, do progresso e da expansão comercial capitalista, algo que vivenciamos, hoje em dia, na bacia do Xingu, com o processo de construção da UHE Belo Monte.

Mesmo assim, não se pode deixar de atentar para a conjuntura política que permitiu, no século $\mathrm{XX}$, que a voz dos grupos sociais diferenciados fosse valorizada na medida de sua importância para contar a versão dos vencidos, descrevendo memórias coletivas de injustiças históricas e a abertura para se pensar o estabelecimento de novos direitos humanos e de seus respectivos destinatários, assim como o fortalecimento dos agentes nos embates e conflitos produzidos com os setores antagônicos. 
O que intermedeia a conexão entre sujeitos diferenciados étnica e culturalmente e o reconhecimento de seus direitos coletivos é a formulação da identidade cultural, construto de apresentação e representação da diferença e que demarca a legitimidade da proposição de direitos diferenciados. Todavia, o desafio está em entender até que ponto as identidades culturais forjadas obtêm reciprocidade nas categorias analíticas construídas, ou melhor, como possibilitar, em tempos de autodefinição dos povos e comunidades tradicionais, a construção de parâmetros (atributos e atribuições) que não fixem ou manipulem a dinâmica sociocultural da diversidade? E, sobretudo, é possível manejar a unificação das identidades culturais na categoria povos e comunidades tradicionais para a criação/efetivação de direitos?

O presente artigo procura problematizar a relação entre direitos e povos/comunidades tradicionais para compreender as formas de construção teórico-normativa da categoria, os pontos de embate e as possíveis contribuições da Antropologia do Direito para desenvolver caminhos de elucidação da relação entre diversidade cultural, categorias analíticas e reconhecimento jurídico.

\section{As construções da categoria povos e comunidades tradicionais}

A categoria ${ }^{1}$ povos e comunidades tradicionais possui um primeiro marco histórico de constituição de vinculação do "tradicional" a determinados segmentos populacionais ligando-os às ideias de entrave ao desenvolvimento (CARNEIRO DA CUNHA; ALMEIDA, 2001), de atraso ou subdesenvolvimento, numa relação dicotômica com as parcelas populacionais industrializadas, inseridas no modo de vida capitalista, tidas, portanto, como ideais civilizacionais. O processo de expansão do povoamento e de modernização da exploração dos recursos naturais, particularmente no Brasil, garantiria a difusão ideológica e superação do tradicionalismo frente ao levante do progresso social e científico.
Os contornos da perspectiva negativa de povos e comunidades tradicionais estão ligados à própria ideia negativa do que seja tradição e conhecimentos tradicionais, invariavelmente referidos à repetição, costume e continuidade via transmissão de geração para geração (DOURADO, 2010), sofrendo transformações (e críticas) estruturais somente na segunda metade do século $\mathrm{XX}$, quando ocorre a associação entre os povos/comunidades e os conhecimentos tradicionais com os novos paradigmas da conservação ambiental, cujo baluarte foi a criação do conceito de desenvolvimento sustentável e o ativismo político-organizacional dos grupos sociais diferenciados que levou para o debate público, nacional e internacional, a visibilidade de relações socioambientais de produção e consumo realizadas de maneira sustentável e, por outro lado, inseridas em dinâmicas de expansão dos empreendimentos capitalista-coloniais que as ameaçavam.

Para Fleury e Almeida, a nova associação foi estabelecida, no Brasil, em meados da década de 80 do século XX, "quando seringueiros assumiram a dianteira ao instaurar a ligação entre sua luta política e preocupações ambientais" (2007, p. 4).

Os povos indígenas, assim como os seringueiros, paulatinamente também foram articulando suas reivindicações políticas às questões ambientais. Ambos emergem na conjuntura sociopolítica da década de 80 do século XX como sujeitos coletivos objetivados em movimentos sociais de âmbito nacional - a União das Nações Indígenas (UNI) e o Conselho Nacional dos Seringueiros (CNS) - que, junto com outros parceiros, tiveram papel fundamental na mobilização e divulgação das violações históricas e atuais cometidas contra seus territórios e modos de vida.

A nova associação tem por finalidade, como bem sintetiza Diegues (2008), demonstrar que povos e comunidades tradicionais, mediante suas práticas culturais, colaboraram e colaboram para a manutenção da biodiversidade, desde que sejam respeitadas, mantidas

\footnotetext{
${ }^{1}$ De acordo com Minayo (2000), as categorias são utilizadas com a finalidade de classificação por intermédio da reunião de grupos de elementos sob título genérico em razão de caracteres comuns. Mais adiante haverá problematização sobre os riscos de instituir elementos classificados aos povos e comunidades tradicionais a partir da ideia de serem comuns a determinados grupos e, portanto, algo que permita "fixar" o correspondente jurídico-analítico de suas identidades culturais.
} 
e garantidas juridicamente suas formas tradicionais de manejo. $^{2}$

A coalização formada entre os movimentos nacionais de seringueiros e indígenas para preservação da floresta amazônica surgida em 1988, no Acre, sob o nome de "Aliança dos Povos da Floresta", o posicionamento marcante dos povos indígenas no Encontro de Altamira de 1989, em protesto à construção da Hidrelétrica de Kararaô, atual UHE Belo Monte, além da participação ativa na assembleia constituinte de elaboração da Constituição Federal de 1988 e na Conferência do Meio Ambiente de 1992 (ECO/92), propiciaram a sedimentação da articulação entre povos/comunidades tradicionais e conservação ambiental e pressionaram o poder público para que implantasse novas leis ou modificasse as normas jurídicas vigentes à época, que desconheciam ou não reconheciam na amplitude desejada os direitos coletivos destes e de outros grupos sociais diferenciados, como os quilombolas e camponeses.

No cenário institucional brasileiro, a recepção da categoria povos e comunidades tradicionais ocorreu com a criação, em 1992, do Centro Nacional de Desenvolvimento Sustentado das Populações Tradicionais (CNPT), como uma divisão dentro do Instituto Brasileiro de Meio Ambiente e Recursos Naturais Renováveis (IBAMA), e ganhou novo fôlego com a implantação do Sistema Nacional de Unidades de Conservação (SNUC - Lei 9.985/2000), em 2000. No âmbito jurídico internacional, o reconhecimento foi obtido na Convenção sobre a Diversidade Biológica (CDB) e na Agenda 21, na Conferência do Rio de Janeiro de 1992 (ECO/92), quando foi atribuído o papel de conservação ambiental às comunidades locais e nativas.

No entanto, o processo de institucionalização normativa e a intensificação do interesse científico, basicamente das Ciências Sociais, conduziram à necessidade de caracterização do que seja a categoria povos e comunidades tradicionais, e é a partir das (disputas de) classificações - ou seja, dos atributos e atribuições geradas que se desenvolvem os paradoxos em torno das possibilidades de utilização da categoria como elemento de reunião da diversidade cultural.

\section{Disputas de classificação e dilemas}

As definições teóricas e normativas sobre povos e comunidades tradicionais sempre esbarraram (e ainda esbarram) na tarefa de recepcionar atributos e atribuições, ou melhor, diretrizes analíticas para encaixe com realidades locais, de modo a (pretensamente) incluir e representar a totalidade dos diversos segmentos diferenciados socioculturalmente da população brasileira.

Para Carneiro da Cunha e Almeida (2001), o emprego do termo "populações tradicionais" é propositalmente amplo sem cair numa confusão conceitual, apesar de ainda estar em sua fase inicial de gestação e, portanto, conviver com dilemas ainda não superados, sobretudo quando passa a traduzir os sujeitos coletivos de direito.

Ainda assim, os autores propõem definição “em extensão" do termo, de enumeração dos membros atuais e os candidatos a membro sob a base comum de serem grupos com baixo impacto ambiental e com interesse de recuperar ou assegurar o controle dos territórios que exploram via comprometimento com a prestação de serviços ambientais. Ao final do texto, surge nova definição que procura apreender as populações tradicionais como

[...] grupos que conquistaram ou estão lutando para conquistar (por meio de meios práticos e simbólicos) uma identidade pública que inclui algumas e não necessariamente todas as seguintes características: o uso de técnicas ambientais de baixo impacto, formas equitativas de organização social, a presença de instituições com legitimidade para fazer cumprir suas leis, liderança local e, por fim, traços culturais que são seletivamente reafirmados e elaborados. (CARNEIRO DA CUNHA; ALMEIDA, 2001, p. 192).

A inserção na categoria deve partir do processo de autoconstituição de cada grupo com requisitos internos

\footnotetext{
${ }^{2}$ Os estudos em Ciências Sociais vieram demonstrar que a revisitação da relação natureza-humano, com base na compreensão dos modos de vida dos povos e comunidades tradicionais, também incluía a atividade humana nas florestas como garante da biodiversidade, é dizer, a biodiversidade atual não existe apesar da habitação humana, mas por causa dela, e a interdição do acesso humano às florestas, dentro da perspectiva ideológica preservacionista, traria como consequência a provável diminuição acentuada da biodiversidade (DIEGUES, 2008).
} 
- estabelecimento de regras de conservação, presença de lideranças e instituições - e externos - alianças com organizações públicas (estatais ou não estatais) e privadas. $\mathrm{Na}$ essência, está a ideia de que a categoria é ocupada por agentes políticos dispostos a estabelecer pacto de compromisso com a conservação ambiental em troca de concessão de certos benefícios, sobretudo do direito à terra e controle/usufruto dos recursos naturais.

Já Little os define considerando "[a] imensa diversidade sociocultural do Brasil [...] e a correspondente diversidade fundiária” (2004, p. 251). Assim, povos e comunidades tradicionais são grupos humanos nomeados sob nomenclaturas diversas e identificados como: comunidades, povos, sociedades, culturas (autóctones, rurais e locais) que, com esforço coletivo, ocupam, usam, controlam e se identificam com um espaço específico, convertendo-o em território que defendem em função de contingências históricas marcadas pelo colonialismo externo e interno.

De acordo com o autor, os vínculos sociais, simbólicos e rituais mantidos pelos grupos sociais com o território estão vinculados à memória e não podem ser confundidos com noções de originalidade da ocupação. O que os distingue e, portanto, unifica é a eterna luta coletiva pela terra, além da presença das seguintes características: regimes de propriedade comum, sentido de pertencimento a um lugar, autonomia cultural e práticas adaptativas sustentáveis.

Diegues parte da definição de culturas tradicionais para sistematizar os elementos comuns dos povos e comunidades tradicionais. Segundo o autor, as culturas tradicionais

[...] são padrões de comportamento transmitidos socialmente, modelos mentais usados para perceber, relatar e interpretar o mundo, símbolos e significados compartilhados, além de seus produtos materiais, próprios do modo de produção mercantil (2008, p. 89).

O que o autor propõe é compreender como se formam as identidades culturais dos grupos ditos "tradicionais" analisando, antes de tudo, sobre que conceito de cultura se está trabalhando a categoria de tradicional e, a partir disso, indicar os elementos comuns destes grupos, resumidos da seguinte forma: (a) dependência e até simbiose com a natureza; (b) conhecimento aprofundado da natureza, passado de geração para geração de forma oral; (c) noção diferenciada de território; (d) moradia e ocupação do território por várias gerações; (e) importância das atividades de subsistência; (f) reduzida acumulação de capital; (g) importância dada à unidade familiar e às relações de parentesco para exercício das atividades econômicas, sociais e culturais; (h) importância das simbologias, mitos e rituais ligados à caça, à pesca e às atividades extrativistas; (i) utilização de tecnologia simples e de baixo impacto ambiental; (j) fraco poder político; (1) auto-identificação ou identificação pelos outros de se pertencer a uma cultura distinta.

Com relação às caracterizações jurídicas, Moreira (2006) e Santilli (2005) elucidam tratar-se de campo ainda mais problemático na construção da categoria, pois não possui consenso nem com relação à própria designação $\mathrm{a}$ utilizar. Assim, se a CDB adotou a locução "comunidades locais e povos indígenas", a Medida Provisória (MP) n. ${ }^{\circ}$ 2.186-16/2001 se refere à "comunidade indígena e comunidade local", a SNUC trabalha com o termo genérico de "populações" e a Lei n. ${ }^{\circ}$ 6.040/2007 trabalha com definição de "povos e comunidades tradicionais".

Por isso, Moreira (2006) opta, "de maneira arbitrária", como ela diz, pela utilização do termo "povos tradicionais", "[...] com o intuito de englobar, ainda que artificialmente, os povos indígenas, quilombolas e as comunidades locais" (2006, p. 44). O termo escolhido está em sintonia com o estabelecido na Convenção $n$. ${ }^{\circ}$ 169 da Organização Internacional do Trabalho (OIT), de 1989, de que grupos indígenas e tribais devem ser identificados como povos que possuem autodefinições e condições sociais, culturais e econômicas distintas de outros segmentos nacionais.

Ainda assim, se a simples (porém complexa) escolha do termo já é extremamente polifônica, imagina-se as características - atributos e atribuições - elencadas para definir as pautas comuns.

No SNUC, a definição de povos e comunidades tradicionais proposta no projeto de lei para o artigo $2^{\circ}$, inciso $\mathrm{XV},{ }^{3}$ foi taxativamente vetada pelo poder executivo, 
com o argumento de que a abrangência do seu conteúdo possibilitaria a inclusão de toda população brasileira ou ao menos toda a população rural de baixa renda, "impossibilitando a proteção especial que se pretende dar às populações verdadeiramente tradicionais" (SANTILLI, 2005, p. 126. Grifos da autora). O interessante é que o movimento dos seringueiros da Amazônia também se mostrou contrário à definição, porém considerando-a excessivamente restritiva.

No entanto, como observa Machado (2009), a não definição explícita no SNUC não impossibilitou que ocorresse junção hermenêutica dos artigos $17, \S \S$ $2^{\circ}$ e $20,{ }^{4}$ para obter a desejada definição de que se trata de população que exista numa área antes da criação da Unidade de Conservação, com sistemas sustentáveis de exploração dos recursos naturais, desenvolvidos ao longo de gerações e adaptados às condições ecológicas locais.

Há, portanto, dois marcadores centrais na definição do SNUC: o tempo de presença e o modo de utilização dos recursos naturais. As possibilidades de permanência territorial e de gestão dos recursos naturais são complementadas pelo direito/dever de participação nos conselhos deliberativos existentes nas Reservas Extrativistas (RESEX) e nas Reservas de Desenvolvimento Sustentável (RESED), com duas restrições relativas à proibição de uso de espécies em extinção e de práticas que impeçam regeneração dos ecossistemas.

Na MP 2.186-16/2001, a definição de "comunidade local" é a de "grupo humano, incluindo remanescentes de comunidades de quilombos, distintos por suas condições culturais, que se organiza, tradicionalmente, por gerações sucessivas e costumes próprios, e que conserva suas instituições sociais e econômicas." Por outro lado, a Portaria n. ${ }^{\circ} 22 / 1992$, do IBAMA, define-as como "comunidades baseadas no extrativismo de bens naturais renováveis" (SANTILLI, 2005, p. 127).

A Política Nacional de Desenvolvimento de Povos e Comunidades Tradicionais (Lei n. ${ }^{\circ}$ 6.040/2007) traz a seguinte definição: "grupos culturalmente diferenciados e que se reconhecem como tais, que possuem formas próprias de organização social, que ocupam e usam territórios e recursos naturais como condição para sua reprodução cultural, social, religiosa, ancestral e econômica, utilizando conhecimentos, inovações e práticas gerados e transmitidos pela tradição".

Por fim, a Convenção 169 da OIT dispõe caracterizações distintas para povos tribais e povos indígenas. No primeiro grupo, afirma serem aqueles "[...] cujas condições sociais, culturais e econômicas distingam-nos de outros segmentos da coletividade nacional e estejam regidos, total ou parcialmente, por seus próprios costumes ou tradições ou por legislação especial." Para o segundo grupo, estabelece serem: “[...] considerados indígenas pelo fato de descenderem de populações que habitavam o país ou região geográfica pertencente ao país na época da conquista ou da colonização ou do estabelecimento de suas fronteiras atuais e que, seja qual for sua situação jurídica, conservam todas as suas próprias instituições sociais, econômicas, culturais e políticas, ou parte delas."

Como se percebe, no âmbito das Ciências Sociais e das normas jurídicas a categoria povos e comunidades tradicionais ainda se configura mais como noção do que como conceito ${ }^{5}$ e pode ser apreendida como significação culturalmente construída e transformada em definição científica.

As diferentes abordagens teórico-normativas apresentam características ditas comuns que repercutem na representação da identidade/imagem dos grupos diferenciados socioculturalmente e, ao mesmo tempo, disputam a primazia de simbolizar a diferença em jogos de poder que, parafraseando Bourdieu (2004), engendram a concorrência pelo monopólio do direito de dizer os direitos da alteridade cultural, num campo discursivo em que se defrontam intelectuais e corpos normativos investidos de competência social e técnica que consiste

\footnotetext{
${ }^{4}$ Os dispositivos legais foram assim definidos: “Art. 17. [...] § 2. ${ }^{\circ}$. Nas Florestas Nacionais é admitida a permanência de populações tradicionais que a habitam quando de sua criação, em conformidade com o disposto em regulamento e no Plano de Manejo da unidade. [...] Art. 20. A Reserva de Desenvolvimento Sustentável é uma área natural que abriga populações tradicionais, cuja existência baseia-se em sistemas sustentáveis de exploração dos recursos naturais, desenvolvidos ao longo de gerações e adaptados às condições ecológicas locais e que desempenham um papel fundamental na proteção da natureza e na manutenção da diversidade biológica." ${ }^{5}$ De acordo com Minayo, as noções são "[...] elementos de uma teoria que ainda não apresentam clareza suficiente e usados como 'imagens' na explicação do real" (2000, p. 93). Logo, são definições prévias ou provisórias mais cercadas de dúvidas e lacunas, do que de certezas e sedimentação teórica que embasam a formação dos conceitos.
} 
precisamente na capacidade de interpretar realidades socioculturais diversas para operar formas de tradução das diferenças - e das violências e lutas surgidas devido às diferenças - em componentes analíticos e direitos específicos, e garantir-lhes a eficácia.

A diferença fica sendo apenas um predicado na compreensão das noções gerais de povos e comunidades tradicionais, bailando pela retórica dialética da fixação de parâmetros comuns e da disposição de elementos de fuga situados na própria pluralidade representacional do "outro". O que há por trás de tudo isso são os jogos de luta pela significação, é dizer, pela apropriação da força simbólica que garanta o efeito de apriorização ${ }^{6}$ (BOURDIEU, 2004) às significações produzidas, de modo a fazer com que os grupos sociais tenham que se enquadrar nos parâmetros estabelecidos para se tornarem ou serem reconhecidos como "povos" e "comunidades" ditos "tradicionais", e não o contrário.

Não se questionam os próprios parâmetros, a não ser na medida em que o questionamento surja para reordenar ou renovar a legitimidade dos parâmetros. E o produto indiretamente cobiçado em todas as significações é a possibilidade de alcançar certa pretensão de universalização dos grupos numa categoria analítica que os represente na integralidade de suas condições físicas e socioculturais.

Ao mesmo tempo, encontra-se a pressão pelo encaixe adequado dos povos e comunidades tradicionais na dinâmica da questão socioambiental, apresentando-os como linha de frente e vanguarda histórica da preservação ambiental, ainda que a associação entre povos/ comunidades tradicionais e biodiversidade tenha servido, nos últimos tempos, também para produzir novas formas de exclusão social devido: (a) à valorização dos conhecimentos tradicionais pela ótica utilitarista-empresarial para a descoberta de "novos produtos" para o mercado global e acoplamento da imagem de sustentabilidade ambiental nas empresas que se consorciam com eles, sem que haja qualquer distribuição equitativa das riquezas (MOREIRA, 2006); (b) à utilização das bandeiras de reconhecimento de direitos de modo inapropriado para o tratamento da diversidade cultural, como ocorreu com relação às RESEX, cujo mesmo modelo foi (e é) imposto para todas as situações que envolvem povos e comunidades tradicionais que se dedicam à atividade extrativista, sem levar em conta as particularidades socioculturais que implicam diferentes modos de lidar com o território, os recursos naturais, as relações de parentesco, entre outros ${ }^{7}$ (SHIRAISHI NETO, 2007); (c) ao interesse ambientalista, travestido em pautas de direitos humanos, de investigar e utilizar seus conhecimentos e modos de vida tradicionais "em favor da conversação", reduzindo a importância dos povos/comunidades à convergência com os objetivos de conservação, o que implica uma série de conflitos que podem ser gerados quando ocorrem mudanças em seus modos de ser, bem como em eventuais aumentos demográficos, mobilidades territoriais e utilização de novos recursos tecnológicos (VIANNA, 2008).

\section{Dinâmica cultural e dificuldades}

Bem dispõem Fleury e Almeida (2007) e Diegues (2008) que quaisquer características apresentadas

\footnotetext{
${ }^{6}$ Para Bourdieu, o efeito de apriorização se inscreve na lógica de funcionamento do campo jurídico e, pode-se dizer, até certo ponto, também do campo científico, "revela-se com toda a clareza na língua jurídica que, combinando elementos directamente retirados da língua comum e elementos estranhos ao seu sistema, acusa todos os sinais de uma retórica da impersonalidade e da neutralidade... [produzindo] dois efeitos maiores. O efeito de neutralização é obtido por um conjunto de características sintáticas tais como o predomínio das construções passivas e das frases impessoais, próprias para marcar a impessoalidade do enunciado normativo e para constituir o enunciador em sujeito universal, ao mesmo tempo imparcial e objectivo. O efeito de universalização é obtido por meio de vários processos convergentes: o recurso sistemático ao indicativo para enunciar normas, o emprego próprio da retórica da atestação oficial e do auto, de verbos atestivos na terceira pessoa do singular do presente ou do passado composto que exprimem o aspecto realizado... o uso de indefinidos... e do presente intemporal - ou do futuro jurídico - próprios para exprimirem a generalidade e a omnitemporalidade da regra do direito... o recurso a fórmulas lapidares e a formas fixas, deixando pouco lugar às variações individuais." (2004, p. 215-216).

7 "O modelo de reserva extrativista que se desenvolveu a partir da experiência dos seringueiros do Acre é um bom exemplo do problema. As reservas extrativistas de babaçu criadas no auge da discussão, década de 1990, têm apresentado desde a sua criação, em 1992, sérias dificuldades na sua implementação. Uma das dificuldades observadas é que o mesmo modelo de unidade de conservação é imposto para todas as situações que envolvem comunidades tradicionais que se dedicam à atividade extrativista, abstraindo suas particularidades. O modelo implantado para as reservas de babaçu tem como ponto de partida as práticas extrativas dos seringueiros, que muito diferem das práticas das chamadas quebradeiras de coco babaçu... Enquanto para os seringueiros o uso do recurso é privado, por unidade familiar, para as quebradeiras de coco, o uso é comum, ficando condicionado à capacidade de cada unidade familiar" (SHIRAISHI NETO, 2007, p. 30).
} 
como pautas comuns para estruturar a categoria povos e comunidades tradicionais, e assim representarem as condições de inclusão e exclusão científico-normativas, se baseiam na noção de tipos ideais e que nenhum povo/ comunidade tradicional existe exatamente no estado descrito textualmente.

Portanto, trata-se de aprender que a forma de apreensão da diferença na categoria criada envolve sua disposição dentro do método tipológico, centrado na criação de tipos ou modelos ideais, construídos a partir da análise de aspectos essenciais do fenômeno analisado, para permitir a identificação de situações e comparação entre elas.

Segundo Marconi e Lakatos (2007), o tipo ideal não existe na realidade, mas serve de modelo de análise e compreensão de casos concretos. Tampouco expressa a totalidade da realidade, apenas os aspectos significativos e os caracteres mais gerais ou regulares.

Os limites de disposição do método tipológico são os próprios limites de compreensão da realidade. A fixação dos atributos e atribuições ideais de personificação dos povos e comunidades tradicionais sempre será vaga ou incompleta porque nunca poderá suprir a totalidade dos elementos presentes em determinada realidade dado o próprio método que o concebe e cujo questionamento quase nunca é feito. A ideia de elencar os fundamentos essenciais dos povos e comunidades tradicionais já contém, em si, o núcleo da inadequação entre categoria analítica e identidade cultural, pois parte de marcadores exógenos para (tentar) traduzir as especificidades nativas, e não o contrário.

Por isso, mais do que descartar a própria categoria, o que se deve ter consciência é de que as lacunas, as fugas e, sobretudo, as incertezas jurídico-científicas sempre irão existir quando se trata de compreender e apreender os fenômenos humanos a partir delas. A diversidade cultural, muito mais do que barreira hermenêutico-normativa, coloca-se como bandeira de inquietação para que sempre se questionem as traduções, pois aqui se esconde o elemento que garante maiores ou menores amplitudes de garantias jurídicas, de efetivo diálogo com os sujeitos coletivos diretamente implicados e, portanto, de reciprocidade para com as diferenças culturais.

$\mathrm{O}$ aspecto central das dificuldades de adequação não está propriamente na categoria povos e comunidades tradicionais, mas no modo como se estabelece a conexão entre tradição e dinâmica cultural.

$\mathrm{O}$ entrelaçamento da tradição com as ideias de continuidade (ALMEIDA, 2006), repetição ou permanência fundamenta perspectiva estanque de cultura, de modo a tratá-la como patrimônio que deve ser preservado e perpetuado ao longo das gerações, um passado que sucumbe o presente para reviver (eternamente) no futuro, ou, como observou Marés (2003), a produção de discurso colonial que representa os povos diferenciados como sendo cultura, enquanto os ocidentais têm cultura.

Pois bem, tal concepção, ainda que vigente na atualidade, passou a ser confrontada e descredibilizada com a emergência das teorias antropológicas que passaram a atentar para o caráter dinâmico da cultura, ou seja, da lógica intrínseca de permanências e mudanças, e de relações interculturais como condições de continuidade/descontinuidade das culturas e das fronteiras étnico-culturais.

Nesse aspecto, relevantes foram as contribuições de Barth (2000) para a renovação teórica da compreensão dos grupos étnicos. O autor propõe que, em vez de considerar os grupos étnicos como "unidades portadoras de cultura", é preciso considerá-los como tipo de organização social que faz uso da identidade étnica, consumando-a por meio de categorias étnicas que visam estabelecer a base das relações interétnicas entre os integrantes do grupo e os não integrantes. Dessa forma, a cultura passa a ser considerada como consequência da organização social do grupo étnico e não mais como elemento básico e gerativo, sendo algumas características dessa cultura utilizadas para estabelecer a particularidade do grupo étnico perante os outros, é dizer, as fronteiras e identidades.

O que Almeida renova dessas considerações é pensar os processos identitários pela ótica da autodefinição, tal qual defende Barth (2000), complementado pela: (a) articulação entre processos identitários e territorialização específica, com a formação de terras de uso comum constituídas por redes de relações sociais surgidas em situações de confronto que delimitam "dinamicamente terras de pertencimento coletivo que convergem para um território" (ALMEIDA, 2008, p. 29), cujos fundamentos "não são redutíveis às oposições usualmente estabelecidas entre o privado e o comunal, entre o individual e o 
coletivo ou entre o legal e o fundado no costume" (ALMEIDA, 2009, p. 59); (b) compreensão da identidade e fronteira étnica como não "coincidindo necessariamente com critérios raciais, culturais ou linguísticos; tampouco se reduz a nacionalidade" (ALMEIDA, 2002, p. 75), pois o componente político-organizativo funciona como aglutinador e explica a capacidade mobilizatória do grupo, inclusive no acionamento estratégico dos marcadores sociais da diferença para fazer frente aos antagonistas sociais e no fortalecimento dos direitos.

A dinamicidade cultural repercute diretamente na construção ideológica do termo tradicional. A integridade da tradição deriva não da persistência sobre o tempo, mas da capacidade de reprodução social de uma comunidade ou população por meio da reinterpretação contínua de seus valores tradicionais. $\mathrm{O}$ "tradicional" passa a ser instrumentalizado pelos grupos como categoria operativa cada vez mais próxima de demandas do presente, cuja significação do conteúdo depende dos modos próprios como os agentes locais representam e definem as relações e as práticas, enfim, o cotidiano de embates e continuidades das tradições étnicas em interação com as "tradições modernas".

Por isso, povos e comunidades tradicionais não estão (e nunca estiveram) à margem das influências e interações com o capitalismo, a globalização econômica e a dita revolução técnico-científico-informacional que intensificaram o processo de uniformização cultural do mundo. Apesar da consequente produção, em muitos casos, de verdadeiros processos desorganizativos, ${ }^{8}$ certo é que a apropriação de determinados padrões de produção e consumo não significa mudança radical dos padrões culturais básicos, mas indica, acima de tudo, a capacidade de mudança social dos povos e comunidades tradicionais e a incapacidade de leitura das novas configurações étnicas (e, portanto, da afirmação ou negação de direitos) caso não sejam relativizadas as próprias categorias analíticas que foram usadas para compreender a realidade.
A tradição aparece (a) como reivindicação que interliga a memória das injustiças históricas com a atualidade das necessidades socioeconômicas e especificidades culturais e como (b) direito involucrado em formas de autodefinição de agentes sociais com existência coletiva. Para Almeida, os povos e comunidades tradicionais aparecem hoje envolvidos num processo de construção do próprio "tradicional", fruto de mobilizações e conflitos,

[...] que tem transformado de maneira profunda as formas de solidariedade apoiadas em relações primárias. Deste ponto de vista, além de ser do tempo presente, o "tradicional" é, portanto, social e politicamente construído (2006, p. 10).

A instrumentalização contemporânea da tradição para servir de suporte às reivindicações políticas de identidades coletivas objetivadas em movimentos sociais afasta por completo a preocupação com os "laços primordiais", com o "isolamento cultural" e a confusão entre "tradição" e "costume" que inviabiliza a percepção dinâmica das práticas jurídicas tradicionais. A tradição vincula-se a processos reais e sujeitos sociais - redefinidos situacionalmente numa mobilização continuada - que transformam dialeticamente suas práticas em demandas do presente, mesmo quando as convertem em normas para fins de interlocução, redefinindo suas relações sociais e com a natureza.

$\mathrm{O}$ direito à tradição recupera não apenas a garantia do direito à cultura, mas a conformação de todas as outras dimensões dos direitos humanos (civis, políticos, sociais, econômicos e ambientais) à repercussão hermenêutico-normativa do direito à diferença, exigindo à adoção de práticas socioinstitucionais estruturadas por meio da perspectiva da interculturalidade ${ }^{9}$ para diálogo com povos e comunidades tradicionais.

\footnotetext{
${ }^{8}$ Segundo Diegues, todos os povos e comunidades tradicionais se encontram articulados e dependentes da formação social capitalista. O grau de dependência varia de contexto para contexto, mas "tem levado a um maior ou menor grau de desorganização das formas pelas quais o pequeno produtor trata o mundo natural e seus recursos" (2008, p. 95-96).

${ }^{9} \mathrm{O}$ conceito de interculturalidade surge no contexto latino-americano para confrontar os conceitos de biculturalidade, surgido nos Estados Unidos, e de multiculturalismo, de ascensão europeia e ampla recepção nos países da América do Norte. A interculturalidade representa um processo de interação social equitativa entre pessoas, conhecimentos e práticas diferentes que parte da reflexão do reconhecimento da diversidade e do respeito às diferenças, mas também da constatação das desigualdades sociais, econômicas, políticas e de gestão do poder, como forma de identificar as hierarquias sociais para compreender os modos como as oportunidades de participação devem ser criadas para garantir a igualdade. Sobre o assunto, consultar: Tubino Arias-Schereiber (2001), Luna Pineda (2009), Servindi (2005) e Santos (2006).
} 
A tarefa será tão mais necessária e, por isso mesmo, tão mais complexa quanto maior o conflito entre autodefinição/dinâmica cultural e os "velhos" referenciais simbólico-normativos reprodutores das ideologias coloniais. Desse modo, alguns focos de tensão hoje são: (a) povos e comunidades tradicionais cujos membros estão localizados no meio urbano, os quais acabam sendo excluídos do reconhecimento identitário pelas instituições públicas por "destoarem" da representação colonial que fixa as possibilidades de afirmação da identidade cultural (e dos direitos coletivos) à territorialidade não urbana, o que resulta na exclusão do acesso diferenciado aos diversos direitos, como saúde, educação e geração de renda; (b) povos e comunidades tradicionais em etnogêneses identitárias, ${ }^{10}$ ditos ressurgidos, que durante muito tempo tiveram que ocultar suas identidades culturais devido às conjunturas políticas coloniais e que hoje, no período de afirmação dos direitos étnicos, têm a chance de emergência pública de suas identidades e de territorialização, mas esbarram na incompreensão de autoridades públicas, mídia e sociedade, que veem tal processo muito mais como oportunismo do que como resgate da dignidade coletiva violada por injustiças históricas; (c) as disputas pelo acesso e gerenciamento do solo e do subsolo nos territórios pertencentes a povos e comunidades tradicionais, onde os conflitos com proprietários privados, processos de desterritorialização ${ }^{11}$ e bio/etnopirataria são constantes; (d) déficit orçamentário das instituições estatais diretamente relacionadas com a promoção de políticas públicas para povos e comunidades tradicionais, além dos entraves políticos e impasses burocrático-administrativos que procrastinam a efetivação do reconhecimento jurídico-formal dos direitos conquistados.

\section{Ciência jurídica e novas possibilidades}

Ainda há outro aspecto da relação entre direitos e categoria analítica, formulado da seguinte maneira: estão ciência e dogmática jurídicas - desenvolvidas na modernidade, mas amparadas em ampla tradição latina que descende de milênios - aptos a recepcionarem as reivindicações políticas de povos e comunidades tradicionais em pautas normativas? Qual o grau de abertura e quais os focos de resistência/conflito que são (e serão) gerados no processo de ressignificação da ciência/dogmática jurídica que a inserção da diversidade cultural passa a exigir, ou seja, de transição paradigmática?

Cabe lembrar o exemplo da construção da categoria sujeito coletivo de direito durante a década de 80 do século XX, no contexto do processo de redemocratização do país, e que emerge das reivindicações políticas dos movimentos sociais que, ao baterem à porta do poder público, sobretudo do poder judiciário, reverberam num vazio normativo que desconhece e desfavorece a replicação das mobilizações políticas em direitos. ${ }^{12}$ Daí o sujeito coletivo operar nesse processo de carência socionormativa percebida como negação de direitos fundamentais que provocou articulação estratégica de lutas para conquistá-los (SOUSA JÚNIOR, 2002).

\footnotetext{
${ }^{10}$ Pacheco de Oliveira analisa os processos de etnogênese ocorridos com os povos indígenas localizados no nordeste brasileiro, indicando abranger "tanto a emergência de novas identidades como a reinvenção de etnias já reconhecidas" (1999, p. 18). Os denominados ressurgidos representam grupos étnicos que sofreram impactos discriminatórios e/ou dizimatórios no período colonial a ponto de terem que negar as identidades étnicas para continuarem a sobreviver em tempos de difícil interação com o Estado-nação e as pautas de soberania territorial. Ainda hoje, povos e comunidades tradicionais ditos ressurgidos têm dificuldade de reconhecimento pelos órgãos estatais e de relação adequada com as sociedades envolventes, em especial nos casos de disputas de terra e de recursos naturais. Sobre o assunto, conferir: Beltrão e Begot (2010), Pacheco de Oliveira (1999), Vaz Filho (2010).

${ }^{11}$ Segundo Almeida e Acevedo Marin (2010), os processos de desterritorialização são sedimentados num conjunto de agroestratégias "que têm sido adotadas pelos interesses empresariais [e também governamentais com interesses político-econômicos privados], vinculados aos agronegócios para incorporar novas terras aos seus empreendimentos econômicos, sobretudo na região amazônica, liberando-as tanto de condicionantes jurídico-formais e político-administrativos quanto de fatores étnicos e culturais ou determinados pelas modalidades de uso de terras tradicionalmente ocupadas por povos indígenas, quilombolas, seringueiros, quebradeiras de coco babaçu, castanheiros, comunidades de fundos de pasto, faxinais, ribeirinhos, geraizeiros e outras categorias sociais" (2010, p. 141). As ações de contenção dos direitos étnicos têm por palco o próprio Estado, ou melhor, os poderes Executivos, Legislativos e Judiciários, que objetivam a neutralização dos mecanismos de liberação e/ou demarcação das terras, haja vista o aumento geral dos preços das commodities no mundo ter impulsionado, no Brasil, o "processo de devastação" (ALMEIDA; SHIRAISHI NETO; MARTINS, 2005) dos territórios, meio ambiente e grupos sociais locais que sofrem o impacto das práticas de exploração intensivo-destrutiva dos recursos naturais e dos seres humanos.

${ }^{12}$ A categoria sujeito coletivo de direito rompe com a estrutura do sujeito individual de direito forjada no domínio do liberalismo (SOUSA JÚNIOR, 2002); agora o destinatário de direitos não é mais o indivíduo - concepção burguesa de subjetividade - e sim determinada realidade ou situação social que, embora coletiva, não se apresenta como portadora da universalidade definida a partir de uma organização que operaria como centro de homogeneização ou reunião.
} 
Convém enfatizar que uma das principais barreiras para a consolidação da categoria sujeito coletivo de direito estava (e ainda está) justamente no âmbito interno da ciência jurídica, cujos tradicionalismo teórico e elitismo dos profissionais constituem verdadeiros obstáculos às pretensões dos movimentos sociais, no sentido amplo, e dos povos e comunidades tradicionais na luta pelo reconhecimento de seus direitos coletivos.

Está-se diante de luta interna no campo jurídico, onde há enfrentamento dos "operadores do direito" em torno do direito de dizer o direito (SHIRAISHI NETO, 2010) e, consequentemente, de dizer o que não é direito: poder de interferir nas estruturas fundacionais do pensamento jurídico moderno de forma a rever noções e princípios profundamente cristalizados e de obrigar o reconhecimento de outras práticas jurídicas para $\mathrm{o}$ reordenamento das hierarquias e normas.

O significado mais visível de uma leitura como a proposta é que o direito possa ir "recuperando" e "atualizando" seus significados no interior da "sociedade plural", que se encontra em processo de profunda transformação (SHIRAISHI NETO, 2007). A possibilidade de democratização do campo de significação da ciência jurídica está necessariamente entrelaçada à potencialização dos limites de compreensão da cultura científica e, desse modo, de abertura intercultural radical para a inserção de referenciais de outras culturas de saberes não científicos, visando ao melhoramento do acesso e da administração da dinâmica jurídica científico-dogmática e, desse modo, ao melhoramento do acesso à justiça social.

Sem dúvida, a disputa pela transformação interna das ciências jurídicas, via entronização do pluralismo cultural no âmago de seus fundamentos científico-normativos, terá sucesso na medida em que possibilitar a inclusão de sujeitos pertencentes aos povos e comunidades tradicionais dentro dos espaços de formação acadêmica e atuação profissional.

Aqui, trata-se de defender a pauta das ações afirmativas como medidas que reordenam as relações de poder nos espaços onde são implantadas, sendo que, no campo da educação universitária, possibilita ao menos três grandes efeitos: (a) disputa interna do paradigma científico pelos povos e comunidades tradicionais, com a transformação da universidade em pluriversidade ${ }^{13}$ pelo revigoramento estabelecido com a experimentação científica por sujeitos oriundos de outras culturas de saberes, não apenas trazendo novos aportes de conteúdo e metodologia, mas interferindo nas estruturas de poder do saber científico; (b) utilização do conhecimento científico para benefício das coletividades de pertença, ante a preocupação política dos sujeitos que ingressam em promoverem retornos sistemáticos aos seus grupos dos conhecimentos aprendidos no âmbito universitário, em diálogo adequado com os conhecimentos tradicionais; (c) abertura para inclusão em diversos campos profissionais antes inacessíveis, ampliando a autodeterminação dos povos e comunidades tradicionais com a possibilidade de terem profissionais advogados, juízes, promotores, professores, médicos, dentistas, entre outros, originários de seus grupos e melhor preparados para intervirem em favor de suas reivindicações e realidades.

Cabe afirmar que a única certeza no campo jurídico, em contato com coletividades diferenciadas culturalmente, é que serão sempre as incertezas (dúvidas, lacunas e imprecisões) que irão reger não somente o contato, mas a fabricação dos direitos e a materialização em cada caso.

Por isso, para Duprat (2007), é tão importante a mudança de postura ética do profissional jurídico da condição de intérprete - e da hegemonia de uma interpretação específica - para a de alguém que compreende, é dizer, de alguém que se desloca do cogito de si mesmo - ou de seu campo jurídico fechado - em direção à prática que se apresenta, e fazê-la falar na exata medida em que aprende a escutar o "outro" que lhe fala as demandas e as formas de conceber os direitos.

\section{Caminhos do reencontro: olhar o novo com novos olhos}

É de Santilli a dica para o caminho que se deve seguir se quisermos realmente propor o reencontro

\footnotetext{
${ }^{13}$ Para Santos (2004), a pluriversidade é a confrontação teórica da relação universidade-ciência, é dizer, de que a universidade constitui-se historicamente como o espaço onde atua somente uma cultura de saber, o saber científico, daí a ideia de universidade. No enfoque da pluriversidade, o espaço universitário passa a abarcar diversas culturas de saberes, muito além do científico, com foco na produção de conhecimentos de forma mais democrática e emancipatória.
} 
adequado do direito com os povos e comunidades tradicionais, ao enfatizar que "a interpretação judicial dos dispositivos do SNUC referentes às populações tradicionais deve-se basear nos conhecimentos antropológicos sobre a matéria" (2005, p. 133). Por óbvio, a autora está falando dos estudos teórico-antropológicos que mapearam as identidades coletivas dos povos e comunidades tradicionais e descreveram, assim como fez a normatividade jurídica, os elementos comuns de pertencimento ou de fixação da diferença.

Talvez seja necessário seguir mesmo os estudos antropológicos, menos no que têm a dizer sobre povos e comunidades tradicionais e mais em como constroem metodológica e eticamente a compreensão da diversidade cultural do "outro".

A perspectiva de atuação da Antropologia no campo jurídico-judicial está irremediavelmente ligada à tradição da pesquisa antropológica e, portanto, à capacidade de valorização heurística das diferenças ao descobri-las no cotidiano via estranhamento do "natural" e a familiarização com o aparentemente "exótico" (KANT DE LIMA, 2007).

AAntropologia coloca o debate da diversidade cultural enquanto condição interna e externa às sociedades que, no jogo do poder, foi hierarquizada e colocada em situação de desigualdade/discriminação para sustentar a predominância de determinados padrões culturais para cumprir interesses político-ideológicos, cujo campo do Direito (ou da dogmática e ciência jurídica) não fugiu à regra, fundado modernamente na concepção de Estado como fonte de produção hegemônica de normas jurídicas que, pela retórica da cidadania, da igualdade e da soberania, tratou de forçar homogeneizações culturais - e a supervalorização da identidade nacional - ou tornar ilegais (no sentido de desvios) práticas e comportamentos que não seguiam a cartilha dos valores instituídos com status de lei.

Por isso, uma das contribuições da Antropologia do Direito ocorreria na tarefa de desnaturalização das construções simbólicas do campo do Direito, primando pelo questionamento do saber-poder desenvolvido enquanto discurso contextualizado, ou seja, produzido por determinados agentes dentro de determinado espaçotempo histórico, tendo em vista trajetórias coletivas e individuais de vida, além das tradições linguísticoculturais que conformam o (e são conformados pelo) modo de pensar e agir.

Nesse ponto, o método etnográfico, aporte central para a coleta de dados no campo antropológico, repercutiria no âmbito jurídico ao indicar que os processos de compreensão das realidades socioculturais estranhas à percepção cultural ocidental devem ser realizados na intensa interação com o "outro", na preocupação com seus significados, com a maneira própria como as pessoas veem a si mesmas, as experiências e o mundo.

Há de se instrumentalizar, cada vez mais, a observação etnográfica para a compreensão das representações e práticas dos próprios agentes sociais que vivenciam e constroem as situações em meio a antagonismos e violências, e por isso mesmo disputam: (a) a inclusão como destinatários dos direitos específicos; (b) o próprio estatuto normativo vigente, de forma a transformá-lo ou efetivá-lo para melhor adequação às reivindicações coletivas formuladas; e (c) participação nos espaços de gestão das políticas públicas, como conselhos, secretarias e ministérios.

Para Almeida (2002), a autodefinição da identidade coletiva e da conformação jurídica estabelece a inversão da legitimidade de representação do "outro", pois não se trata mais de fazer valer o que as agências institucionais, as ONGs ou o que algum partido político define como sendo aqueles agentes sociais, e sim como os próprios sujeitos se autorrepresentam e quais critérios político-organizativos que orientam suas mobilizações e forjam a coesão em torno de uma identidade.

A incorporação da identidade coletiva para as mobilizações e lutas, por uma diversidade de agentes sociais, pode (e deve) ser mais ampla do que a abrangência de critérios morfológicos e descritivos, pois é papel da diversidade e da dinâmica cultural romper as barreiras dos supostos universalismos conceituais jurídicos para fazer enxergar, pelos mesmos olhos que antes tudo achavam já terem enxergado, as inúmeras cegueiras socionormativas que traduzem cenários de exclusão social e inadequação jurídica.

Por outro lado, a incorporação dos critérios etnográficos também exigiria a busca pela relativização de hipóteses, conceitos e classificações, de modo a controlar 
as preconcepções dos enfoques teóricos e dos valores culturais no contato com outras culturas de saberes. ${ }^{14}$

Para tanto, faz-se necessária a abertura de espaços de diálogo intercultural, espaços participativos já garantidos normativamente por meio do artigo $6^{\circ}$ do Convênio 169 da OIT e do artigo 231, $\S 3^{\circ}$, da CRFB, mas que ainda carecem de regulamentação dos procedimentos a serem adotados e, sobretudo, da ética a ser corporificada na interação entre sujeitos de diferentes culturas de saberes e interesses políticos antagônicos.

Os espaços de negociação e tomada de decisão precisam se adaptar e flexibilizar a forma de participação social de povos e comunidades tradicionais, pois somente assim será possível efetivar a democracia participativa pela lógica da diversidade cultural. Inovar a prática democrática implica a promoção de rupturas com modelos de participação estabelecidos e a criação de novas determinações participativas de inclusão dos grupos como sujeitos de direitos - destinatários de normas jurídicas - e sujeitos do direito - coprodutores das normas jurídicas por meio da inclusão nos espaços institucionais de criação e administração das mesmas.

\section{Referências}

ALMEIDA, A. W. B. Os quilombos e as novas etnias. In: O'DWYER, E. C. (Org.). Quilombos: identidade étnica e territorialidade. Rio de Janeiro: FGV/ABA, 2002.

. Arqueologia da tradição: uma apresentação da Coleção "Tradição \& Ordenamento Jurídico". In: SHIRAISHI NETO, J. (Org.). Leis do babaçu livre: práticas jurídicas das quebradeiras de coco babaçu e normas correlatas. Manaus: PPGSCA-UFAM/ Fundação Ford, 2006.

Terras tradicionalmente ocupadas: processos de territorialização, movimentos sociais e uso comum. In:

(Org.). Terra de quilombo, terras indígenas, "babaçuais livres", "castanhais do povo", faxinais e fundos de pastos: terras tradicionalmente ocupadas. Manaus: PGSCA-UFAM, 2008.

Terras de preto, terras de santo, terras de índio: uso comum e conflito. In: GODOI, E. P.; MENEZES, M. A.;
Daí porque o caráter processual da participação será tão ou mais importante que o direito substantivo à participação para definir o grau de protagonismo dos sujeitos e grupos envolvidos, pois se trata de entender que, dependendo do modo como os procedimentos são construídos e executados para materializar a ação participativa, ter-se-ão maiores ou menores possibilidades de efetivar esse direito na plenitude das condições que povos e comunidades tradicionais consideram satisfatórios.

Logo, relativizar a categoria povos e comunidades tradicionais significa abrir espaço para a compreensão da impossibilidade de reciprocidade completa, em qualquer tempo e espaço, da categoria analítica com as realidades locais, um distanciamento crítico que questiona a incompletude teórico-normativa e, ao mesmo tempo, dispõe-se a compreender o infinito da diferença cultural num trabalho etnográfico e participativo permanentemente enredado no controle dos etnocentrismos e preconceitos, pois para descobrir é preciso relacionar-se e, no momento mesmo da descoberta, colocar-se na situação de aprendiz e, tal qual sugere Woortmann, "[...] deixar claro que 'aqui o senhor é meu professor'. Por favor, explique-me o trabalho na roça e desculpe alguma pergunta boba" (2009, p. 128).
ACEVEDO MARIN, R. (Orgs.). Diversidade do campesinato: expressões e categorias; v. 2: Estratégias de reprodução social. São Paulo: Editora UNESP; Brasília: Núcleo de Estudos Agrários e Desenvolvimento Rural, 2009.

; SHIRAISHI NETO, J.; MARTINS, C. C. Guerra ecológica nos babaçuais: o processo de devastação das palmeiras, a elevação do preço de commodities e aquecimento do mercado de terras na Amazônia. São Luís: Lithograf, 2005.

; ACEVEDO MARIN, R. Campanha de (des)territorialização na Amazônia: o agronegócio e a reestruturação do mercado de terras. In: BOLLE, W.; CASTRO, E.; WEJMELKA, M. (Orgs.). Amazônia: região universal e teatro do mundo. São Paulo: Globo, 2010.

BARTH, Frederik. Os grupos étnicos e suas fronteiras. In: (Org.). O guru, o iniciador e outras variações antropológicas. Rio de Janeiro: Contra Capa Livraria, 2000.

\footnotetext{
${ }^{14}$ Em sintonia com a proposta de Almeida de que "[...] as respostas têm que vir da intensificação do trabalho etnográfico, identificando e analisando detalhadamente situações concretas e evitando a linguagem classificatória das regras e das predefinições” (2002, p. 74).
} 
BELTRÃO, J. F.; BEGOT, M. Fronteiras forjadas, "pertenças" ocultas: a propósito de "gênesis" identitárias entre os Timbira Ocidentais (Sudeste do Pará - Brasil). In: CONGRESSO DO CONSELHO EUROPEU DE PESQUISAS SOCIAIS SOBRE AMÉRICA LATINA (CEISAL). 6., 2010. Anais... Toulouse-França, 2010.

BOURDIEU, P. O poder simbólico. Rio de Janeiro: Bertrand Brasil, 2004.

BRASIL. Constituição da República Federativa do Brasil de 1988. Disponível em: <http://www.planalto.gov.br/ccivil_03/ constituicao/constitui\%C3\%A7ao.htm>. Acesso em: fev. 2012.

. Lei $n^{\circ} 9.985$ de 18 de julho de 2000 (Sistema Nacional de Unidades de Conservação). Disponível em: <http:// www.planalto.gov.br/ccivil_03/leis/L9985.htm>. Acesso em: mar. 2012.

. Medida Provisória n. ${ }^{\circ}$ 2.186-16, de 23 de agosto de 2001. Disponível em: <http://www.planalto.gov.br/ccivil_03/ mpv/2186-16.htm>. Acesso em: fev. 2012.

Decreto $n{ }^{\circ} 6040$ de 7 de fevereiro de 2007. Disponível em: <http://www.planalto.gov.br/ccivil_03/_ato20072010/2007/Decreto/D6040.htm>. Acesso em: mar. 2012.

CARNEIRO DA CUNHA, M.; ALMEIDA, M. W. B. Populações tradicionais e conservação ambiental. In: CAPOBIANCO, J. (Org.). Biodiversidade amazônica. Avaliação e ações prioritárias para a conservação, uso sustentável e repartição de beneficios. São Paulo: Estação Liberdade; Instituto Socioambiental, 2001.

CIMI. História dos povos indígenas: 500 anos de luta no Brasil. Petrópolis, RJ: Vozes, 1982.

DIEGUES, A. C. O mito moderno da natureza intocada. São Paulo: HUCITEC; NAPAUB/USP, 2008.

DOURADO, S. B. Os conhecimentos tradicionais como objeto de disputas no campo: a diversidade dos sentidos relacionais. In: ALMEIDA, A. W. B. (Org.). Conhecimentos tradicionais e territórios na Pan-Amazônia. Manaus: UEA Editores, 2010.

DUPRAT, D. Prefácio. In: SHIRAISHI NETO, J. Direito dos povos e das comunidades tradicionais no Brasil: declarações, convenções internacionais e dispositivos jurídicos definidores de uma política nacional. Manaus: UEA, 2007.

FLEURY, L. C.; ALMEIDA, J. Populações tradicionais e conservação ambiental: uma contribuição da teoria social. Revista Brasileira de Agroecologia, v. 2, n. 3, p. 3-19, 2007.

KANT DE LIMA, Roberto. Por uma Antropologia do Direito no Brasil. In: CERQUEIRA, D. T.; FRAGALE FILHO, R. (Orgs.). $O$ ensino jurídico em debate: o papel das disciplinas propedêuticas na formação jurídica. Campinas, SP: Millennium Editora, 2007.

LITTLE, P. E. Territórios sociais e povos tradicionais no Brasil: por uma Antropologia da Territorialidade. Anuário Antropológico/2002-2003, Rio de Janeiro, p. 251-290, 2004.

LUNA PINEDA, F. Un acercamiento a la interculturalidad. 2009. Disponível em: <http://www.caaap.org.pe/archivos/ interculturalidad.pdf $>$. Acesso em: abr. 2011.

MACHADO, P. A. L. Direito Ambiental Brasileiro. São Paulo: Malheiros Editores, 2009.

MARCONI, M. A.; LAKATOS, E. M. Metodologia científica. São Paulo: Atlas, 2007.

MARÉS, C. F. Multiculturalismo e direitos coletivos. In: SANTOS, B. S. (Org.). Reconhecer para libertar: os caminhos do cosmopolitismo multicultural. Rio de Janeiro: Civilização Brasileira, 2003.

MINAYO, M. C. S. O desafio do conhecimento: pesquisa qualitativa em saúde. São Paulo/Rio de Janeiro: Hucitec/ Abrasco, 2000.

MOREIRA, E. A proteção jurídica dos conhecimentos tradicionais associados à biodiversidade: entre a garantia do direito e a efetividade das políticas públicas. Tese (Doutorado em Desenvolvimento Sustentável do Trópico Úmido) - Universidade Federal do Pará-UFPA. Belém, 2006.

ORGANIZAÇÃO INTERNACIONAL DO TRABALHO. Convenção $n .{ }^{\circ} 169$ sobre povos indigenas e tribais em países independentes. Disponível em: $<$ http://www.oitbrasil.org.br/>. Acesso em: fev. 2012.

PACHECO DE OLIVEIRA, J. Uma etnologia dos "índios misturados"? Situação colonial, territorialização e fluxos culturais. In: (Org.). A viagem da volta. Etnicidade, politica e reelaboração cultural no Nordeste indígena. Rio de Janeiro: Contra Capa, 1999.

SANTILLI, J. Socioambientalismo e novos direitos: proteção jurídica à diversidade biológica e cultural. São Paulo: Peirópolis, 2005.

SANTOS, B. S. A universidade no século XXI: para uma reforma democrática e emancipatória da universidade. São Paulo: Cortez, 2004.

. A gramática do tempo: para uma nova cultura política. São Paulo: Cortez, 2006.

SERVINDI. Interculturalidad: desafio y proceso em construcción - manual de capacitación. Lima: SINCO Editores, 2005. 
SHIRAISHI NETO, J. A particularização do universal: povos e comunidades tradicionais face às declarações e convenções internacionais. In: Direito dos povos e das comunidades tradicionais no Brasil: declarações, convenções internacionais e dispositivos jurídicos definidores de uma política nacional. Manaus: UEA, 2007.

"Novas sensibilidades", velhas decisões: notas sobre as transformações jurídicas recentes. In: ENCONTRO ANUAL DA ANDHEP, 6., 2010. Anais... Brasília, ANDHEP, 2010. Disponível em: $<$ http://www.andhep2010.sinteseeventos.com. br>. Acesso em: nov. 2011.

SOUSA JÚNIOR, J. G. Movimentos sociais - emergência de novos sujeitos: o sujeito coletivo de direito. In: Sociologia Jurídica: condições sociais e possibilidades teóricas. Porto Alegre: Sergio Fabris Editor, 2002.

TUBINO ARIAS-SCHREIBER, F. Interculturalizando el multiculturalismo. In: ENCUENTRO INTERNACIONAL
SOBRE INTERCULTURALIDAD. Balance y perspectiva. Barcelona, Fundação CIBOD, 2001. Disponível em: <www. cidob.org>. Acesso em: set. 2011.

VAZ FILHO, F. A. Povos indígenas e etnogêneses na Amazônia. In: LUCIANO, G. J. S.; OLIVEIRA, J. C.; HOFFMAN, M. B. (Orgs.). Olhares indigenas contemporâneos. Brasília: Centro Indígena de Estudos e Pesquisas, 2010.

VIANNA, L. P. De invisiveis a protagonistas: populações tradicionais e unidades de conservação. Rio de Janeiro: Annablume/FAPESP, 2008.

WOORTMANN, E. F. O saber camponês: práticas ecológicas tradicionais e inovações. In: GODOI, E. P.; MENEZES, M. A.; ACEVEDO MARIN, R. (Orgs.). Diversidade do campesinato: expressões e categorias; v. 2: Estratégias de reprodução social. São Paulo: Editora UNESP; Brasília: Núcleo de Estudos Agrários e Desenvolvimento Rural, 2009.

Recebido em 29 de julho de 2012. Aceito em 29 de janeiro de 2013. Publicado em junho de 2013. 